\title{
Assessment of the Nutritional Situation of Elderly Nursing Home Residents in Vienna
}

\author{
D. Kulnik I. Elmadfa \\ Department of Nutritional Sciences, University of Vienna, Vienna, Austria
}

\section{Key Words}

Elderly nutrition - Nutritional status, elderly •

Mini Nutritional Assessment $\cdot$ Dietary intake, elderly •

Weighed food intake method

\begin{abstract}
Background: In Austria, reliable information about the nutritional situation of institutionalized, frail elderly is lacking. Methods: MNA (Mini Nutritional Assessment) and NuRAS (Nutritional Risk Assessment Scale), tools specifically developed to evaluate the nutritional status of the elderly, were used for the assessment of the general nutritional and health status of the residents. Individual intake of energy and nutrients was measured by using the weighed food intake method during 7 consecutive weekdays. Results: According to MNA results $(n=245), 13.9 \%$ had a satisfactory nutritional status, $48.3 \%$ were assessed as 'at risk of malnutrition', and $37.8 \%$ as being 'malnourished'. There is evidence that the number of assessed nutritional risk factors has an impact on the nutritional status. Further, there is a link between the assessed nutritional status and the individual nutrient intake of the residents. Conclusion: There is evidence for nutritional problems in frail, institutionalized elderly nursing home residents. The MNA seems to be a reliable tool to identify individuals at risk for malnutrition. Strategies for effective
\end{abstract}

nutritional intervention should be implemented in longterm care facilities for the elderly in order to prevent and treat malnutrition and to ensure high-quality care.

Copyright $\odot 2008$ S. Karger AG, Basel

\section{Methods Used}

Residents of a large Viennese nursing home (longterm care; mean age: $86 \pm 7$ ) were invited to participate in the study.

MNA (Mini Nutritional Assessment) and NuRAS (Nutritional Risk Assessment Scale) [1], tools specifically developed to evaluate the nutritional status of the elderly, were used for the assessment of the general nutritional and health status of the residents. The MNA was chosen because it was specifically developed to evaluate the nutritional status of the elderly and is widely used and accepted today. It was shown to be a reliable tool for nutritional assessment of frail or institutionalized elderly too, with high sensitivity $(96 \%)$ in evaluating nutritional status in frail elderly [2-4]. The validated questionnaire is administered in 2 stages (screening and assessment). The full MNA includes 18 items grouped into 4 categories: anthropometric assessment (BMI calculated from weight and height, weight loss, and arm and calf circumferenc-

\section{KARGER \\ Fax +4161306 1234 E-Mail karger@karger.ch} www.karger.com
(C) 2008 S. Karger AG, Basel 0250-6807/08/0525-0051\$24.50/0

Accessible online at:

www.karger.com/anm
Daniela Kulnik

Universität Wien, Abteilung für Ernährungswissenschaften

Althanstrasse 14

AT-1090 Wien (Austria)

Tel. +43 14277 549, Fax +43 1427795 49, E-Mail daniela.kulnik@danone.com 
es); general assessment (lifestyle, medication, mobility and presence of signs of depression or dementia); short dietary assessment (number of meals, food and fluid intake, and anatomy of feeding), and subjective assessment (self-perception of health and nutrition) [5]. The individual intake of energy and nutrients was measured by using the weighed food intake method during 7 consecutive weekdays.

\section{Characterization of the Residents - General Nutritional and Health Status}

The residents were classified into different levels of dependency, level 1 representing the lowest and level 7 the highest. Level 1-2 has been assigned to $5.2 \%$, level 3-4 to $35.1 \%$, level $5-6$ to $55.9 \%$ and level 7 to $3.9 \%$ of the residents. $64.1 \%$ of the residents are bedridden, $19.2 \%$ are housebound and $16.7 \%$ can move outdoors. While 50\% of the residents with the lower level of dependency (level 1-3) have a satisfactory nutritional status (according to MNA results), only $10 \%$ with level of dependency $4-7$ have a satisfactory nutritional status and $90 \%$ are at risk for malnutrition or malnourished.

According to the MNA results $(\mathrm{n}=245), 13.9 \%$ had a satisfactory nutritional status, $48.3 \%$ were assessed as 'at risk of malnutrition' and $37.8 \%$ as being 'malnourished'.

The most frequently present nutritional risk factors amongst the residents are high drug consumption (97\%), difficulty in cutting food (70.6\%), depressive illness (63\%), gait disorder (57\%), and mental/cognitive impairment (52\%).

\section{Nutrient Intake}

89 nursing home residents were analyzed by weighed food intake analysis during 7 consecutive weekdays. Subsequently, 21 residents were excluded and therefore 68 residents represented the final sample for the nutrient intake calculation. Results have been compared to the $\mathrm{DACH}$ reference values for nutrient intake [6].

The mean basic metabolic rate (BMR) of the elderly, calculated on weight $(\mathrm{kg})$ and height (meters) according to Schofield [7] for 60 - to 100 -year-olds is $5.7 \mathrm{MJ} /$ day for men and $4.9 \mathrm{MJ} /$ day for women. The mean energy requirement (ER), estimated from BMR and PAL (physical activity level), is $6.6 \mathrm{MJ}$ for women and 7.2 MJ for men. The mean energy intake of the nursing home residents was 6.6 MJ (6.5 MJ for men and 6.6 MJ for women). Mea- sured energy intake of $23.5 \%$ of the elderly is lower than the calculated BMR and approximately $50 \%$ of the sample cannot reach the estimated ER. The mean carbohydrate intake was $186 \mathrm{~g} /$ day. The carbohydrate intake provided $49.8 \% \mathrm{E}$. The recommended level of at least $50 \% \mathrm{E}$ was not reached by $53 \%$ of the residents. The mean intake of sucrose was around one third of the total carbohydrate intake. The mean total fat intake was $60 \mathrm{~g} /$ day. The fat intake provided $35 \% \mathrm{E}$, which exceeds the upper limit for fat (related to light work) set by the guiding values of DACH. The mean intake of saturated fat was on average $16 \%$ of total food energy ( $49 \%$ of the total fat intake) and therefore beyond the recommended $10 \%$ level. Mean dietary cholesterol intake was $254 \mathrm{mg} /$ day. The 7-day mean of $75 \%$ residents does not exceed the upper limit of dietary cholesterol intake which is $300 \mathrm{mg} /$ day.

The mean protein intake was $52 \mathrm{~g} /$ day or $0.9 \mathrm{~g} / \mathrm{kg} /$ day corresponding to $14 \%$ of the energy intake (E\%) from protein. $44.6 \%$ ate less than $0.8 \mathrm{~g}$ protein $/ \mathrm{kg} / \mathrm{day}$, implying a risk of negative nitrogen balance [8]. Mean intakes of vitamin $\mathrm{D}, \mathrm{E}$, thiamine, pantothenic acid, vitamin $\mathrm{B}_{6}$ (men only), folate and cobalamine are lower than reference values (DACH, 2000). Mineral intake below recommendation are $\mathrm{Ca}, \mathrm{Mg}$ and zinc (women only). Intake of energy, water, fat, dietary fiber, starch, vitamin $\mathrm{D}$, niacin and sodium is correlated to the MNA score.

\section{Conclusion}

There is evidence for nutritional problems in frail, institutionalized elderly nursing home residents. The number of nutritional risk factors has an impact on the nutritional status. Furthermore, there is a link between the assessed nutritional status and the individual nutrient intake of the residents.

\section{Disclosure Statement}

The study received funding by Novartis. 


\section{References}

1 Nikolaus T, Bach M, Siezen S, Volkert D, Oster P, Schlierf G: Assessment of nutritional risk in the elderly. Ann Nutr Metab 1995;39: 340-345.

2 Guigoz Y: The mini nutritional assessment (MNA) review of the literature: What does it tell us? J Nutr Health Aging 2006;10:466485 .
-3 Sieber CC: Nutritional Screening tools: How does the MNA ${ }^{\circledR}$ compare? Proceedings of the Session Held in Chicago May 2-3, 2006 (15 Years of Mini Nutritional Assessment). J Nutr Health Aging 2006;10:488-492.

4 Vellas B, Villars H, Abellan G, et al: Overview of the MNA: its history and challenges. J Nutr Health Aging 2006;10:456-463.

5 Lauque S, Nourhashemi F, Vellas B: Nutritional evaluation tools in the elderly; in Seiler WO, Stähelin HB (eds): Malnutrition in the Elderly. Darmstadt, Steinkopf, 1999.
6 German Nutrition Society, Austrian Nutrition Society, Swiss Society for Nutrition Research, Swiss Nutrition Association: Reference Values for Nutrient Intake (D-A-CH). Frankfurt am Main, Umschau/Braus, 2000.

7 Schofield DA: Predicting basal metabolic rate: new standards and review of previous work. Hum Nutr Clin Nutr 1985;39:5-41.

8 WHO: Energy and protein requirements: report of a joint FAO/WHO/UNU Expert Consultation. World Health Organ Tech Rep Ser 1985;724:1-206. 